\title{
Concentration-dependent effects of paeoniflorin on proliferation and apoptosis of vascular smooth muscle cells
}

\author{
YANAN GUO, YINTAO ZHAO, LING LI, XIAOYUN WEI, PINGJUN GAO, \\ YANQIANG ZHOU, YUAN LIU and HAIBO YANG
}

Department of Cardiology, The First Affiliated Hospital of Zhengzhou University, Zhengzhou, Henan 450000, P.R. China

Received November 6, 2016; Accepted July 27, 2017

DOI: $10.3892 / \mathrm{mmr} .2017 .7776$

\begin{abstract}
Vascular smooth muscle cells (VSMCs) are an important component of arterial walls, and their dysfunction may serve an important role in the development of cardiovascular diseases, including atherosclerosis and restenosis. Paeoniflorin (PF) is a principal component of the commonly used traditional Chinese medicine, peonies. To the best of our knowledge, the effects of PF on apoptosis and proliferation of VSMCs and its underlying molecular mechanisms have not been widely reported. Therefore, the present study was designed to investigated this phenomenon. VSMCs were treated with different concentrations of $\mathrm{PF}(25,50$ and $100 \mu \mathrm{g} / \mathrm{ml}$ ) for 12,24 or $48 \mathrm{~h}$. The data demonstrated that PF treatment not only significantly decreased cell viability and DNA synthesis but also blocked G0/G1 cell cycle progression. This effect was associated with a decreased expression of cyclin D1, cyclin E, cyclin-dependent kinase (CDK)4 and CDK2 as well as an upregulation of p21. Notably, a significant concentration-dependent decrease in the phosphorylation of p65 and nuclear factor of $\kappa$ light polypeptide gene enhancer in B-cells inhibitor- $\alpha$ ( $\mathrm{I \kappa B} \alpha$ ) was observed. In addition, it was demonstrated that PF promoted the apoptosis of VSMCs, which was associated with the increased expression of caspases. In conclusion, PF inhibited the proliferation of VSMCs by
\end{abstract}

Correspondence to: Dr Yuan Liu or Dr Haibo Yang, Department of Cardiology, The First Affiliated Hospital of Zhengzhou University, 1 Jianshe East Road, Zhengzhou, Henan 450000, P.R. China

E-mail: 393362091@qq.com

E-mail: yanghaibo1975@126.com

Abbreviations: CDK, cyclin-dependent kinase; VSMCs, vascular smooth muscle cells; PF, paeoniflorin; $\mathrm{I} \kappa \mathrm{B} \alpha$, nuclear factor of $\kappa$ light polypeptide gene enhancer in B-cells inhibitor- $\alpha$; NF- $\kappa \mathrm{B}$, nuclear factor- $\kappa \mathrm{B}$; CCK, cell counting kit; FITC, fluorescein isothiocyanate; PI, propidium iodide; RT-qPCR, reverse transcription-quantitative polymerase chain reaction; DAPI, 4',6-diamidino-2-phenylindole; TUNEL, terminal deoxynucleotidyl transferase dUTP nick-end labeling; PDGF, platelet-derived growth factor

Key words: paeoniflorin, vacular smooth muscle cells, proliferation, apoptosis, nuclear factor- $\kappa \mathrm{B}$ downregulating proteins associated with the nuclear factor- $\kappa \mathrm{B}$ signaling pathway. Furthermore, it promoted the apoptosis of VSMCs by upregulating the expression of caspases. These results may be useful in improving the understanding of the molecular mechanisms underlying the apoptotic and anti-proliferative effects of PF on VSMCs, and facilitate the development of novel treatments for cardiovascular diseases.

\section{Introduction}

Vascular smooth muscle cells (VSMCs) are an essential component of arterial walls (1), and their dysfunction may result in pathological processes and cause cardiovascular diseases. For example, over-proliferation or reduced apoptosis of VSMCs contributes to the development of atherosclerosis (2) and in-stent restenosis (ISR) (3). However, the underlying mechanisms are not fully understood.

Over the past few years, an increasing number of studies have indicated the important contribution of the nuclear factor (NF) $-\kappa B$ signaling pathway in the proliferation of VSMCs $(4,5)$. NF- $\mathrm{KB}$ dimers exist in the cytoplasm as cytoplasmic latent complexes consisting of three subunits: p50, p65 and nuclear factor of $\kappa$ light polypeptide gene enhancer in B-cells inhibitor- $\alpha(\mathrm{I} \kappa \mathrm{B} \alpha)$ (6). Following exposure to proinflammatory stimuli, I $\mathrm{K} \mathrm{B} \alpha$ is rapidly phosphorylated and can be degraded by the $26 \mathrm{~S}$ proteasome. This action results in the nuclear translocation of NF- $\mathrm{\kappa B}$ dimers, which then bind to specific DNA sites ( $\kappa \mathrm{B}$ sites) (7), leading to the transcription of NF- $\kappa B$ regulated genes and proliferation of VSMCs.

Paeoniflorin (PF) is one of the principal bioactive ingredients of peonies, which have been used in traditional Chinese medicine for $>1,200$ years (8). Accumulating evidence has demonstrated that PF exerts anti-cancer $(9,10)$, anti-atherosclerosis (11) and immunoregulatory (12) pharmacological activities, with low toxicity and few side effects. Recent findings by Lee et al (13) have revealed that PF significantly inhibits the proliferation and migration of platelet-derived growth factor (PDGF)-BB-stimulated VSMCs. However, its effects on the proliferation and apoptosis of VSMCs and the underlying molecular mechanisms are still unknown.

The present study investigated the anti-proliferative and apoptotic effects of PF on VSMCs and explored the possible underlying mechanisms. To the best of our knowledge, this study demonstrated for the first time that PF inhibits 
proliferation and promotes apoptosis of VSMCs by inhibiting the NF- $\mathrm{kB}$ signaling pathway and increasing caspase expression, respectively. Therefore, PF may be a potential therapeutic strategy for the treatment of atherosclerosis and ISR.

\section{Materials and methods}

Culture of VSMCs. The mouse aorta smooth muscle cell line was purchased from China Center for Type Culture Collection (Shanghai, China). The cells were cultured in Dulbecco's modified Eagle's medium (Gibco; Thermo Fisher Scientific, Inc., Waltham, MA, USA) supplemented with $1 \%$ penicillin-streptomycin and 10\% fetal bovine serum (FBS; Gibco; Thermo Fisher Scientific, Inc.), and were maintained at $37^{\circ} \mathrm{C}$ in a humidified atmosphere of $5 \% \mathrm{CO}_{2}$. Cell culture passage numbers 4-6 were used for experiments.

Cell counting kit (CCK)-8 assay and bromodeoxyuridine (BrdU) incorporation assays of VSMCs. The viability of VSMCs was detected using a CCK-8 assay (Dojindo Molecular Technologies, Inc., Kumamoto, Japan). Briefly, cells were transferred to a 96 -well plate $\left(2 \times 10^{5}\right.$ cells $\left./ \mathrm{ml}\right)$ and incubated with fresh medium at $37^{\circ} \mathrm{C}$ in $5 \% \mathrm{CO}_{2}$ for $24 \mathrm{~h}$. Following this, the cells were pretreated with PF (Shanghai Winherb Medical S\&T Development Co., Ltd., Shanghai, China) for 12, 24 or $48 \mathrm{~h}$. CCK-8 solution $(10 \mu \mathrm{l})$ was then added to each well, followed by a 2 -h incubation. The optical density at $450 \mathrm{~nm}$ was read using a microplate reader and the cell viability was subsequently expressed as a percentage of the control groups.

The proliferation of PF-treated VSMCs was studied using a BrdU incorporation assay (Roche Applied Science, Mannheim, Germany). VSMCs were cultured in a 6-well plate $\left(2 \times 10^{5}\right.$ cells $\left./ \mathrm{ml}\right)$ with $10 \% \mathrm{FBS}$ for $48 \mathrm{~h}$ and then serum-starved by incubating without FBS for $24 \mathrm{~h}$. The VSMCs were subsequently pretreated with $\mathrm{PF}(25,50$ or $100 \mu \mathrm{g} / \mathrm{ml})$ for 12,24 or $48 \mathrm{~h}$ and then the proliferation was measured using BrdU incorporation assays. The optical density was measured at $370 \mathrm{~nm}$ using an enzyme-linked immunosorbent assay (ELISA) plate reader.

Annexin V-fluorescein isothiocyanate (FITC)/propidium iodide (PI) assay of VSMCs. The effects of PF on the cell cycle of VSMCs were analyzed using an Annexin V-FITC/PI flow cytometric assay (BD Biosciences, Franklin Lakes, NJ, USA) according to the manufacturer's protocol. The VSMCs were cultured in a 6-well plate at a density of $1 \times 10^{5} /$ well with $\mathrm{PF}(50$ and $100 \mu \mathrm{g} / \mathrm{ml}$ ) for $24 \mathrm{~h}$, washed once with phosphate-buffered saline (PBS), and then centrifuged at $2,067 \mathrm{x}$ g and at $4{ }^{\circ} \mathrm{C}$ for $5 \mathrm{~min}$, followed by resuspension in $500 \mu \mathrm{l}$ binding buffer. Next, the VSMCs were incubated with Annexin-V-FITC for $20 \mathrm{~min}$, followed by PI for $10 \mathrm{~min}$ at room temperature, and then the apoptotic cells were evaluated using a BD FACSCanto ${ }^{\mathrm{TM}}$ II flow cytometry system (BD Biosciences).

Reverse transcription-quantitative polymerase chain reaction (RT-qPCR) assay of VSMCs. The results of the previous experiments in this study indicated that the optimal concentration of PF was $100 \mu \mathrm{g} / \mathrm{ml}$; therefore, this was used in subsequent experiment with VSMCs. Total RNA was extracted using TRIzol reagent (Invitrogen; Thermo Fisher Scientific, Inc.) according to the manufacturer's protocol after the VSMCs were treated with PF (100 $\mu \mathrm{g} / \mathrm{ml})$ for $24 \mathrm{~h}$. To synthesize cDNA, $2 \mu \mathrm{l}$ total RNA was reverse-transcribed using a cDNA synthesis kit (Roche Applied Science). qPCR was performed using SYBR green PCR master mix (Roche Applied Science) according to the manufacturer's protocol. The Light Cycler 480 instrument with designated software (version 1.5; Roche Diagnostics, Basel, Switzerland) was used for PCR amplifications. The PCR thermal cycling protocol was as follows: 1 cycle of initial denaturation at $94^{\circ} \mathrm{C}$ for $2 \mathrm{~min}$, followed by 40 cycles of denaturation at $94^{\circ} \mathrm{C}$ for $40 \mathrm{sec}$, annealing at $58^{\circ} \mathrm{C}$ for $45 \mathrm{sec}$ and extension at $72^{\circ} \mathrm{C}$ for $1 \mathrm{~min}$. The following primer sequences were used: Cyclin D1 forward, 5'-CCCGAGGAGTTGCTG CAAATGGA-3' and reverse, 5'-AGGGCCACAAAGGTC TGTGCA-3'; cyclin E forward, 5'-TGGTGTCCTCGCTGC TTCTGCT-3' and reverse, 5'-TGCTTGGGCTTTGTCCAG CAAG-3'; cyclin-dependent kinase (CDK)4 forward, 5'-CAA TGTTGTACGGCTGATGG-3' and reverse, 5'-GGAGGTGCT TTGTCCAGGTA-3; CDK2 forward, 5'-GCTTTCTGCCAT TCTCATCG-3' and reverse, 5'-GTCCCCAGAGTCCGAAAG AT-3; and p21 forward, 5'-GCTTTCTGCCATTCTCATCG-3' and reverse, 5'-TCGCCATGAGCGCATCGCAAT-3'; GAPDH forward, 5'-GACATGCCGCCTGGAGAAAC-3' and reverse, 5'-AGCCCAGGATGCCCTTTAGT-3'. GAPDH served as a reference gene. The $2^{-\Delta \Delta C q}$ method was used to analyze data from qPCR experiments (14).

Terminal deoxynucleotidyl transferase deoxyuridine 5'-triphosphate nick-end labeling (TUNEL)/4', 6-diamidino-2-phenylindole (DAPI) assays of VSMCs. The TUNEL analysis (Vazyme, Piscataway, NJ, USA) was used to detect the DNA fragments generated during apoptosis. Briefly, VSMCs were cultured on chamber slides and the cells were pretreated with PF $(50,100 \mu \mathrm{g} / \mathrm{ml})$ for $24 \mathrm{~h}$. Subsequently, cells were fixed with $2 \%$ paraformaldehyde and incubated with the TUNEL assay reagents for $1 \mathrm{~h}$ at $37^{\circ} \mathrm{C}$. The nuclei were stained with DAPI for $10 \mathrm{~min}$, and then the cells were imaged using fluorescence microscopy. The percentage of apoptotic cells was calculated as the ratio of the TUNEL-positive (stained green) to the total of DAPI-positive (stained blue) cells.

Western blot analysis of VSMCs. VSMCs were cultured in $100 \mathrm{~mm}$ petri dishes and pretreated with $\mathrm{PF}(25,50$ and $100 \mu \mathrm{g} / \mathrm{ml})$ for 3 and $24 \mathrm{~h}$ for phosphorylated-protein and protein expression determination, respectively. After incubation, the cells were lysed with radioimmunoprecipitation assay buffer (Beyotime Institute of Biotechnology, Haimen, China), and centrifuged at $2,067 \mathrm{x}$ g at $4^{\circ} \mathrm{C}$ for $10 \mathrm{~min}$. Cell lysates (50 ug samples) were separated by $10 \%$ SDS-PAGE, followed by electrotransfer to polyvinylidene fluoride membranes (EMD Millipore, Billerica, MA, USA). Subequently, the membranes were blocked with $5 \%$ non-fat milk at room temperature for $3 \mathrm{~h}$ and incubated with primary antibodies overnight at $4^{\circ} \mathrm{C}, \mathrm{p} 65$ (1:1,000; cat. no. 8242; Cell Signaling Technology, Inc., Danvers, MA, USA), p-P65 (1:1,000; cat. no. 3033; Cell Signaling Technology, Inc.), IкB $\alpha$ (1:1,000; cat. no. 4814P; Cell Signaling Technology, Inc.), p-IкB $\alpha$ (1:1,000; cat. no. 2859P; Cell Signaling Technology, Inc.), GAPDH (1:1,000; cat. no. 2118; Cell Signaling Technology, Inc.), rabbit monoclonal cleaved (c)-caspase-3 (1:1,000; cat. no. 9664; Cell Signaling Technology, Inc.), rabbit polyclonal c-caspase-8 
A

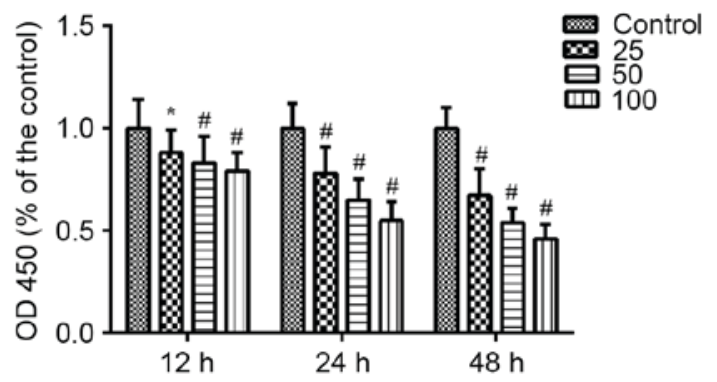

B

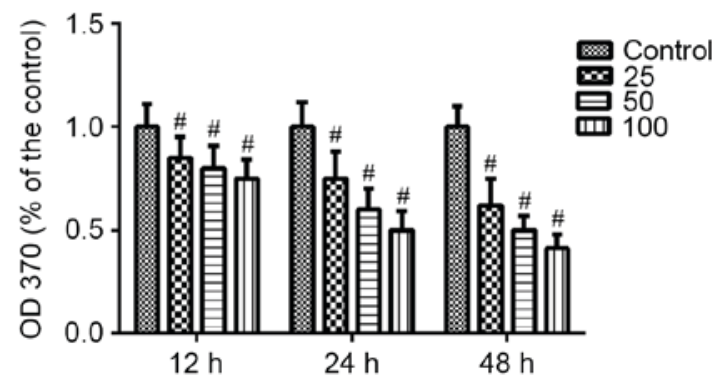

Figure 1. Effect of paeoniflorin (PF, 25, 50, and $100 \mu \mathrm{g} / \mathrm{ml}$ ) on VSMC viability and proliferation. (A) After 12, 24 or 48 h, VSMC viability was detected using a Cell Counting kit-8 assay. (B) VSMC proliferation was detected using a bromodeoxyuridine assay. Data are expressed as the mean \pm standard deviation. ${ }^{*} \mathrm{P}<0.05$ and ${ }^{*} \mathrm{P}<0.01$ vs. control group. VSMC, vascular smooth muscle cell; OD, optical density.

A

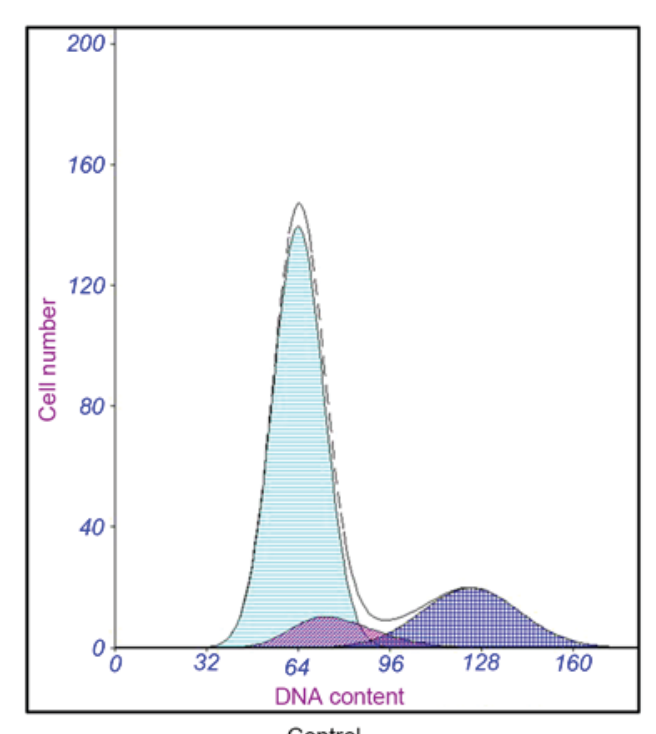

C

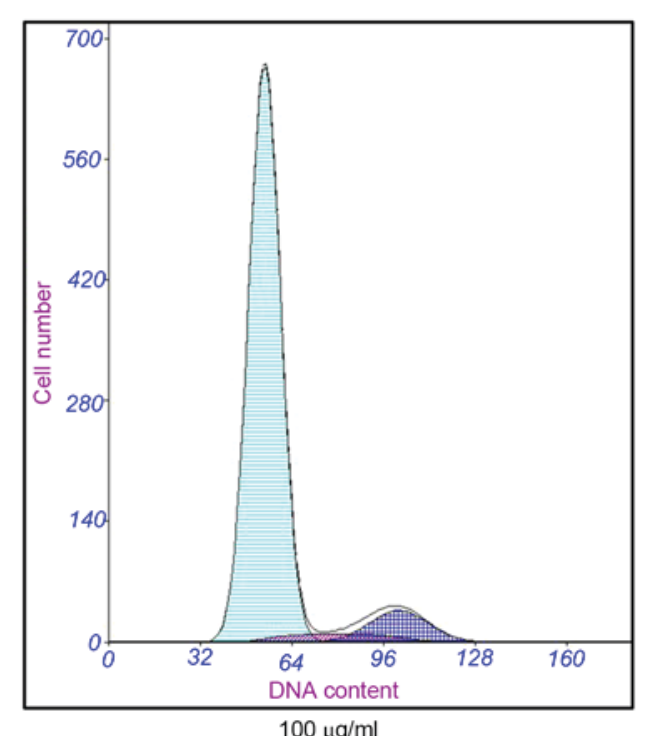

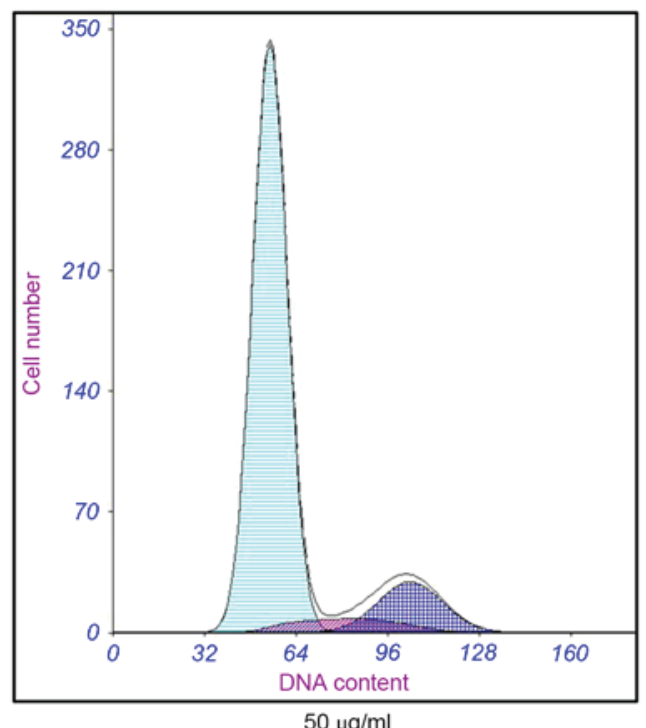

D

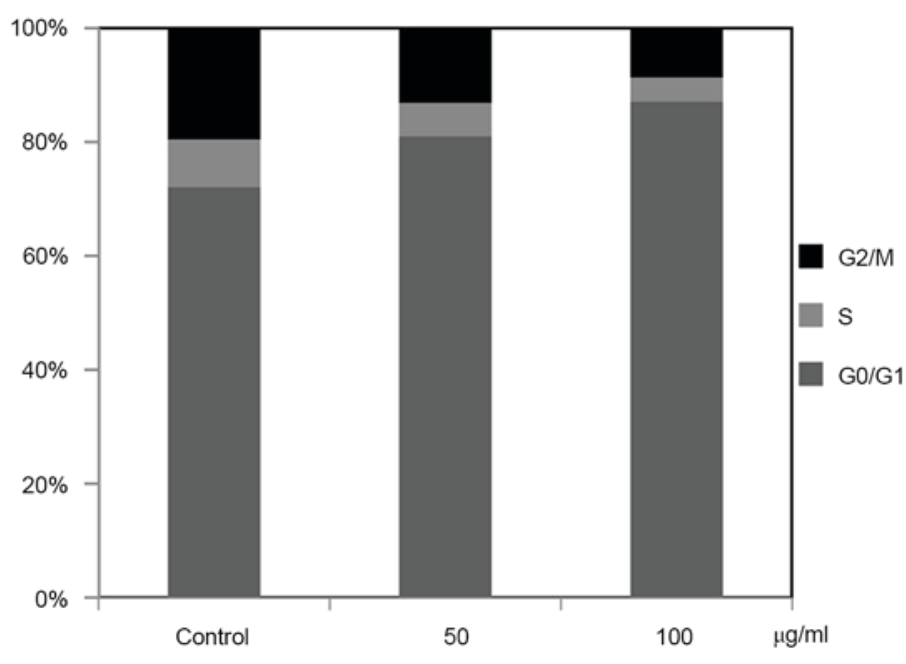

Figure 2. Effects of PF on cell cycle of VSMCs. Flow cytometry evaluation using Annexin-V fluorescein isothiocyanate/propidium iodide demonstrated the effects of $24 \mathrm{~h}$ treatment with (A) 0, (B) 50 and (C) $100 \mu \mathrm{g} / \mathrm{ml}$ PF on VSMCs. (D) Percentages of cells at different phases in each group. PF, paeoniflorin; VSMC, vascular smooth muscle cell.

(1:1,000; cat. no. 9429; Cell Signaling Technology, Inc.), rabbit polyclonal c-caspase-9 (1:1,000; cat. no. 9509P; Cell Signaling
Technology, Inc.). This was followed by incubation with the secondary antibody, goat anti-rabbit immunoglobulin G (1:100; 
cat. no. 926-32211; LI-COR Biosciences, Lincoln, NE, USA), at room temperature for $60 \mathrm{~min}$. The western blots were scanned using a two-color infrared Odyssey imaging system (version 3.0, LI-COR Biosciences, USA) to quantify the protein expression.

Statistical analysis. Statistical analysis was performed using SPSS version 17.0 (SPSS, Inc., Chicago, IL, USA). Data are expressed as the mean \pm standard deviation. The different groups were compared using one-way analysis of variance followed by Student-Newman-Keuls tests. $\mathrm{P}<0.05$ was considered to indicate a statistically significant difference.

\section{Results}

Effects of PF on VSMC viability and proliferation. The effects of PF on the viability and proliferation of VSMCs were measured using CCK- 8 and BrdU assays. VSMCs cultured with PF $(25,50$ and $100 \mu \mathrm{g} / \mathrm{ml})$ for 12,24 or $48 \mathrm{~h}$ exhibited decreased viability compared with the control group $(\mathrm{P}<0.05$; Fig. 1A). Similarly, PF reduced BrdU incorporation in VSMCs $(\mathrm{P}<0.01$; Fig. 1B). Both assays demonstrated that $\mathrm{PF}$ inhibited cell viability and proliferation in a time- and concentration-dependent manner.

Effects of PF on cell cycle of VSMCs. The potential altering effect of PF on the cell cycle of VSMCs was analyzed. The results demonstrated that the percentage of cells in the G1 phase increased from 72.1 to $80.4 \%$ and 72.1 to $87.5 \%$ in the control and $\mathrm{PF}$-treated groups, respectively ( $\mathrm{P}<0.05$ vs. control group). Furthermore, the control and PF-treated cells in the S phase decreased from 8.4 to $7.4 \%$ and 8.4 to $4.3 \%$, respectively ( $\mathrm{P}<0.05$ vs. control group), while the $\mathrm{G} 2$ phase cells decreased from 19.5 to $12.6 \%$ and 19.5 to $8.2 \%$, respectively ( $\mathrm{P}<0.05$ vs. control group, Fig. 2). These results indicated that PF induced G1 cell cycle arrest in the VSMCs, and the percentage of the S and $\mathrm{G} 2 / \mathrm{M}$ phase cells decreased significantly.

Effects of PF on the expression and activation of cell cycle-associated molecules. To investigate the specific underlying mechanism of $\mathrm{PF}$, its effects on cell cycle regulatory proteins were determined in VSMCs at the predetermined optimal concentration ( $100 \mu \mathrm{g} / \mathrm{ml}$ for $24 \mathrm{~h}$ ) by using RT-qPCR . Pre-treatment with PF significantly decreased the expression levels of cyclin D1, cyclin E, CDK4 and CDK2 compared with the levels of the untreated control cells $(\mathrm{P}<0.05)$. However, PF enhanced the expression of p21 (Fig. 3). These findings demonstrated that the inhibitory effect of PF on VSMCs may be associated with cell cycle inhibition.

Effects of $P F$ on expression of $N F-\kappa B$ signaling pathway molecules. The levels of NF- $\mathrm{KB}$ signaling pathway proteins in VSMCs cultured with PF $(25,50$ and $100 \mu \mathrm{g} / \mathrm{ml})$ for $3 \mathrm{~h}$ were analyzed using western blotting. The results demonstrated that PF significantly decreased the phosphorylation of p65 and $\mathrm{I} \kappa \mathrm{B} \alpha$ in a concentration-dependent manner $(\mathrm{P}<0.05$; Fig. 4). However, PF had no effect on the expression of un-phosphor-

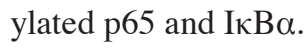

Effects of PF on apoptosis of VSMCs. The apoptotic effects of PF on VSMCs were determined using the TUNEL assay,

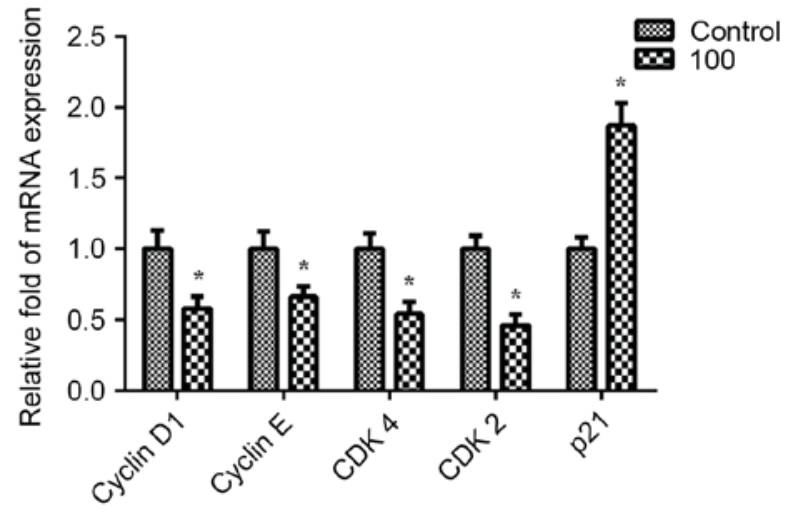

Figure 3. mRNA expression of cell cycle-associated genes in vascular smooth muscle cells. Paeoniflorin $(100 \mu \mathrm{g} / \mathrm{ml}$ for $24 \mathrm{~h})$ inhibited mRNA expression of the cell cycle regulatory proteins cyclin D1, cyclin E, CDK4 and CDK2, and up-regulated p21 mRNA expression. Data are expressed as the mean \pm standard deviation. ${ }^{*} \mathrm{P}<0.05$ vs. control. $\mathrm{CDK}$, cyclin-dependent kinase.

which revealed that treatment with PF (50 and $100 \mu \mathrm{g} / \mathrm{ml}$ ) for $24 \mathrm{~h}$ significantly increased the cells with fragmented DNA (Fig. 5A). As presented in Fig. 5B, the percentage of TUNEL-positive cells in the control, and the 50 and $100 \mu \mathrm{g} / \mathrm{ml}$ groups, was $0 \pm 0,19.8 \pm 1.2$ and $61.3 \pm 1.5$, respectively. Therefore, these results suggested that PF induced the apoptosis of VSMCs.

Effects of PF on caspase expression. A significant increase in caspase-3 expression was observed when VSMCs were cultured with PF $(25,50$, and $100 \mu \mathrm{g} / \mathrm{ml})$ for $24 \mathrm{~h}$ (Fig. 6). Similarly, PF significantly enhanced the expression of caspase-8 and -9 in a concentration-dependent manner ( $\mathrm{P}<0.01$ vs. control group).

\section{Discussion}

The present study had two major findings. Firstly, PF exhibited an inhibitory effect on VSMC proliferation as demonstrated by the results of the CCK-8, BrdU and Annexin-V FITC/PI assays. Notably, the results of western blot analysis demonstrated that modulation of the NF- $\mathrm{KB}$ signaling pathway might be an important contributing signal by inhibiting of the phosphorylation of $\mathrm{p} 65$ and IкB $\alpha$. Secondly, PF enhanced VSMC apoptosis, as was demonstrated by the TUNEL assay. This enhancement of apoptosis may be associated with increased expression of caspases. Previous findings by Guo et al (15) demonstrated that PF reversed ischemia-induced activation of the NF- $\mathrm{kB}$ signaling pathway and has potential neuroprotective effects. These results indicated that PF may be a good candidate for the prevention of atherosclerosis and vascular restenosis. Several previous studies have reported the effect of $\mathrm{PF}$ on the proliferation of human lung cancer (9), gastric carcinoma (16) and breast cancer cells (17). In addition, Wu et al (18) demonstrated that PF suppresses NF- $\mathrm{KB}$ activation by modulating IкB $\alpha$ and enhancing 5-fluorouracil-induced apoptosis of human gastric carcinoma cells. The abnormal proliferation of VSMCs in arterial walls is known to be an important pathogenic factor for atherosclerosis and restenosis following angioplasty. Furthermore, Jeong et al (19) demonstrated that 
A

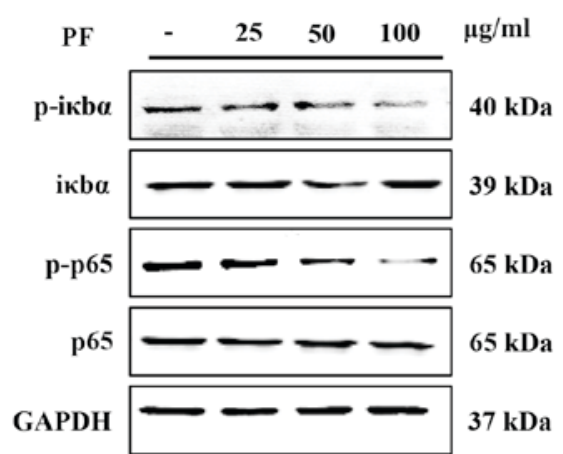

B

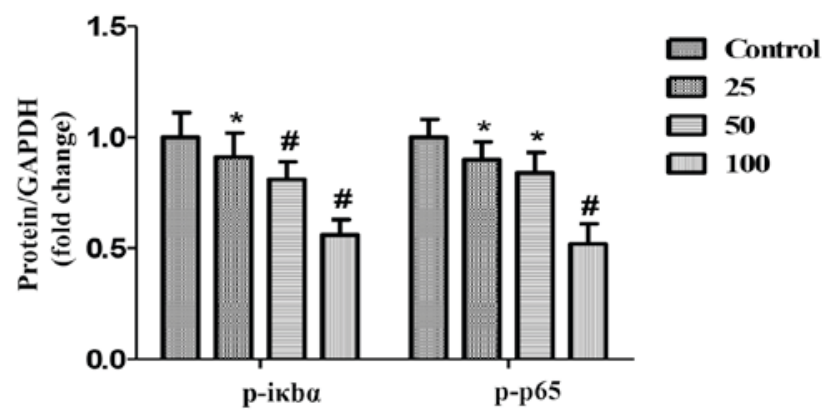

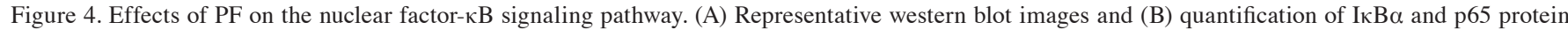
expression levels. Data are expressed as the mean \pm standard deviation. ${ }^{*} \mathrm{P}<0.05$ and ${ }^{\#} \mathrm{P}<0.01$ vs. control group. I $\kappa \mathrm{B} \alpha$, nuclear factor of $\kappa$ light polypeptide gene enhancer in B-cells inhibitor- $\alpha$; p-, phosphorylated; PF, paeoniflorin.
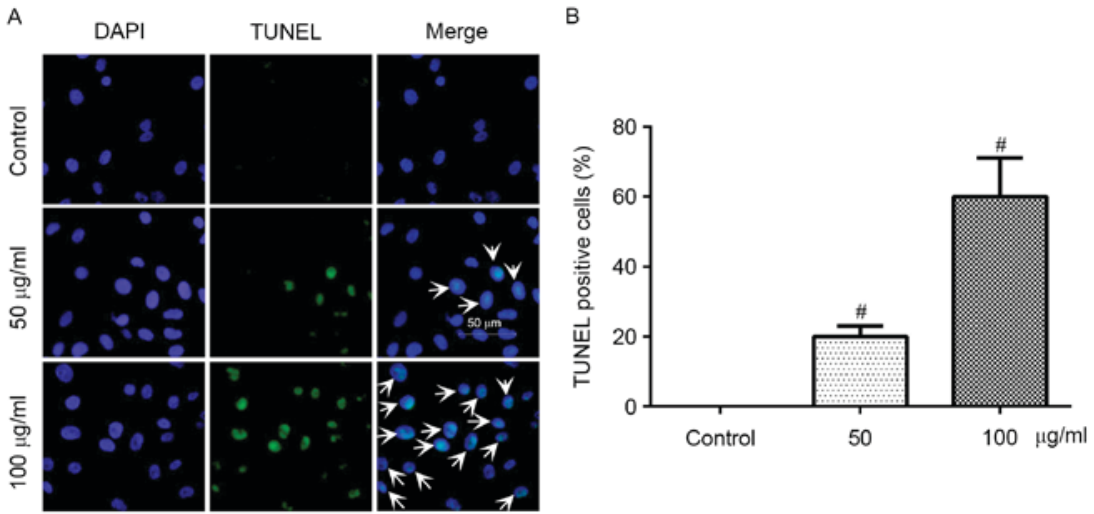

Figure 5. Apoptotic effects of paeoniflorin (50 and $100 \mu \mathrm{g} / \mathrm{ml}$ for $24 \mathrm{~h}$ ) on VSMCs. (A) Fluorescence images and (B) quantification of TUNEL-positive cells (indicated by white arrows) in VSMCs. Green fluorescence, TUNEL-psotiive cells; blue fluorescence, DAPI nuclear staining. Data are expressed as the mean \pm standard deviation. ${ }^{~} \mathrm{P}<0.01 \mathrm{vs}$. control. TUNEL, terminal deoxynucleotidyl transferase deoxyuridine 5 '-triphosphate nick-end labeling; DAPI, 4',6-diamidino-2-phenylindole.

A

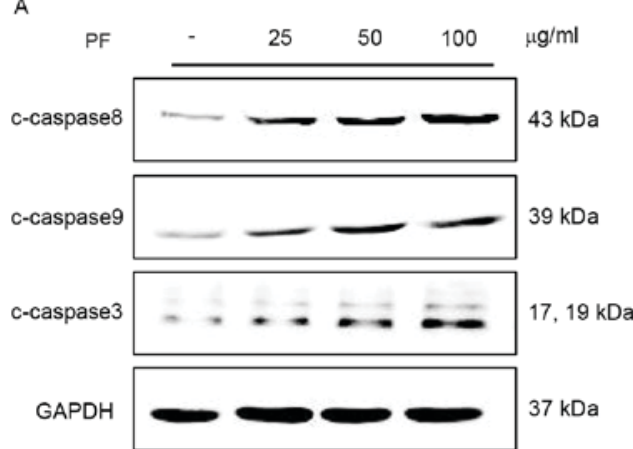

B

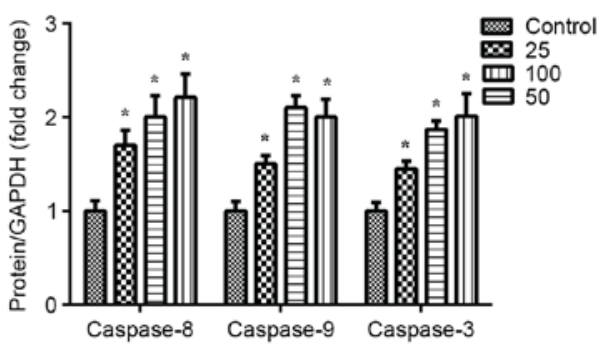

Figure 6. PF increases caspase-3, -8 and -9 expression levels. (A) Representative western blot images and (B) quantification of expression levels of caspase-3, -8 and -9 increased in vascular smooth muscle cells cultured with PF for $24 \mathrm{~h}$. Data are expressed as the mean \pm standard deviation. ${ }^{\mathrm{P}}<0.05$ vs. control group. $\mathrm{PF}$, paeoniflorin.

the inhibition of NF- $\kappa \mathrm{B}$ activity prevents high glucose-induced VSMC proliferation.

The association between the NF- $\mathrm{KB}$ signaling pathway and the anti-proliferative effect of PF on VSMCs has not been well reported. Therefore, the present study investigated the effects of PF at different concentrations $(25,50$ and $100 \mu \mathrm{g} / \mathrm{ml})$ in
VSMC models. The data indicated that treatment with PF significantly inhibited the proliferation of VSMCs in a time- and concentration-dependent manner, which was confirmed using CCK-8, BrdU and flow cytometry analyses. This experiment confirmed that the optimal concentration of PF was $100 \mu \mathrm{g} / \mathrm{ml}$, which was used in the subsequent experiments with VSMCs. 
The results demonstrated that $\mathrm{PF}$ treatment inhibited the proliferation of VSMCs by downregulating the expression of four proteins involved in the G0/G1 and G1/S transition (cyclin D1, cyclin E, CDK4 and CDK2). Furthermore, PF upregulated the expression of $\mathrm{p} 21$, which is known to form heterotrimetric complexes with cyclin-CDK complexes, thereby inhibiting their activity. Finally, the western blot analysis data, which provided insights into the mechanism of this phenomenon, revealed that $\mathrm{PF}(25,50$ and $100 \mu \mathrm{g} / \mathrm{ml})$ decreased the phosphorylation of p65 and $\mathrm{I} \kappa \mathrm{B} \alpha$ in a concentration-dependent manner. These results indicated that PF exerted an inhibitory effect on VSMCs proliferation by inhibiting activation of the $\mathrm{NF}-\kappa \mathrm{B}$ signaling pathway.

Numerous studies have demonstrated that VSMC apoptosis occurs during physiological vessel remodelling, including after flow reduction (20), atherosclerosis (21) and after injury (22). However, the apoptotic effect of PF on VSMCs is not widely reported. Thus, the TUNEL assay results demonstrated that PF significantly increased the apoptosis of VSMCs. Furthermore, the effect on VSMCs apoptosis was confirmed by upregulation of caspase- $3,-8$ and -9 expression.

In conclusion, the results of the present study suggested that PF has anti-proliferative effects in VSMCs, which likely involve the NF- $\kappa \mathrm{B}$ signaling pathway. In addition, $\mathrm{PF}$ promoted the apoptosis of VSMCs by upregulating the expression of caspases. Therefore, PF may have the potential for further development as a candidate chemo-preventive or therapeutic agent for the treatment of arteriosclerosis and restenosis.

\section{References}

1. Ross R: Cell biology of atherosclerosis. Annu Rev Physiol 57: 791-804, 1995.

2. Lusis AJ: Atherosclerosis. Nature 407: 233-241, 2000.

3. Davies MG and Hagen PO: Pathobiology of intimal hyperplasia. Br J Surg 81: 1254-1269, 1994.

4. Su G, Sun G, Liu H, Shu L, Zhang J, Guo L, Huang C and Xu J: Niacin suppresses progression of atherosclerosis by inhibiting vascular inflammation and apoptosis of vascular smooth muscle cells. Med Sci Monit 21: 4081-4089, 2015.

5. Yang J, Chen L, Ding J, Fan Z, Li S, Wu H, Zhang J, Yang C, Wang $\mathrm{H}$, Zeng $\mathrm{P}$ and Yang J: MicroRNA-24 inhibits high glucose-induced vascular smooth muscle cell proliferation and migration by targeting HMGB1. Gene 586: 268-273, 2016.

6. Bonizzi G and Karin M: The two NF-kappaB activation pathways and their role in innate and adaptive immunity. Trends Immunol 25: 280-288, 2004.

7. Li ZW, Chu W, Hu Y, Delhase M, Deerinck T, Ellisman M, Johnson R and Karin M: The IKKbeta subunit of IkappaB kinase (IKK) is essential for nuclear factor kappaB activation and prevention of apoptosis. J Exp Med 189: 1839-1845, 1999.
8. Wu H, Zhu Z, Zhang G, Zhao L, Zhang H, Zhu D and Chai Y: Comparative pharmacokinetic study of paeoniflorin after oral administration of pure paeoniflorin, extract of Cortex Moutan and Shuang-Dan prescription to rats. J Ethnopharmacol 125: 444-449, 2009.

9. Li CR, Zhou Z, Zhu D, Sun YN, Dai JM and Wang SQ: Protective effect of paeoniflorin on irradiation-induced cell damage involved in modulation of reactive oxygen species and the mitogen-activated protein kinases. Int J Biochem Cell Biol 39: 426-438, 2007.

10. Hung JY, Yang CJ, Tsai YM, Huang HW and Huang MS: Antiproliferative activity of paeoniflorin is through cell cycle arrest and the Fas/Fas ligand-mediated apoptotic pathway in human non-small cell lung cancer A549 cells. Clin Exp Pharmacol Physiol 35: 141-147, 2008.

11. Hsu FL, Lai CW and Cheng JT: Antihyperglycemic effects of paeoniflorin and 8-debenzoylpaeoniflorin, glucosides from the root of Paeonia lactiflora. Planta Med 63: 323-325, 1997.

12. Zheng YQ, Wei W, Zhu L and Liu JX: Effects and mechanisms of Paeoniflorin, a bioactive glucoside from paeony root, on adjuvant arthritis in rats. Inflamm Res 56: 182-188, 2007.

13. Lee KP, Kim JE, Kim H, Chang HR, Lee DW and Park WH: Bo-Gan-Whan regulates proliferation and migration of vascular smooth muscle cells. BMC Complement Altern Med 16: 306 , 2016.

14. Livak KJ and Schmittgen TD: Analysis of relative gene expression data using real-time quantitative PCR and the 2(-Delta Delta C(T)) method. Methods 25: 402-408, 2001.

15. Guo RB, Wang GF, Zhao AP, Gu J, Sun XL and Hu G: Paeoniflorin protects against ischemia-induced brain damages in rats via inhibiting MAPKs/NF- $\kappa \mathrm{B}$-mediated inflammatory responses. PLoS One 7: e49701, 2012.

16. Zheng YB, Xiao GC, Tong SL, Ding Y, Wang QS, Li SB and Hao ZN: Paeoniflorin inhibits human gastric carcinoma cell proliferation through up-regulation of microRNA-124 and suppression of PI3K/Akt and STAT3 signaling. World J Gastroenterol 21: 7197-7207, 2015.

17. Zhang Q, Yuan Y, Cui J, Xiao T and Jiang D: Paeoniflorin inhibits proliferation and invasion of breast cancer cells through suppressing Notch-1 signaling pathway. Biomed Pharmacother 78: 197-203, 2016.

18. Wu H, Li W, Wang T, Shu Y and Liu P: Paeoniflorin suppress NF-kappaB activation through modulation of I kappaB alpha and enhances 5-fluorouracil-induced apoptosis in human gastric carcinoma cells. Biomed Pharmacother 62: 659-666, 2008.

19. Jeong IK, Oh DH, Park SJ, Kang JH, Kim S, Lee MS, Kim MJ, Hwang YC, Ahn KJ, Chung HY, et al: Inhibition of NF- $\mathrm{BB}$ prevents high glucose-induced proliferation and plasminogen activator inhibitor-1 expression in vascular smooth muscle cells. Exp Mol Med 43: 684-692, 2011.

20. Cho A, Mitchell L, Koopmans D and Langille BL: Effects of changes in blood flow rate on cell death and cell proliferation in carotid arteries of immature rabbits. Circ Res 81: 328-337, 1997.

21. Lutgens E, de Muinck ED, Kitslaar PJ, Tordoir JH, Wellens HJ and Daemen MJ: Biphasic pattern of cell turnover characterizes the progression from fatty streaks to ruptured human atherosclerotic plaques. Cardiovasc Res 41: 473-479, 1999.

22. Ashino T, Yamamoto M and Numazawa S: Nrf2/Keap1 system regulates vascular smooth muscle cell apoptosis for vascular homeostasis: Role in neointimal formation after vascular injury. Sci Rep 6: 26291, 2016. 